\title{
Quantification of 3/4D ultrasound pelvic floor changes induced by postpartum muscle training in patients with levator ani muscle avulsion: a parallel randomized controlled trial
}

\author{
José Antonio Sainz-Bueno ${ }^{1,2}$, María José Bonomi ${ }^{1}$, Carmen Suárez-Serrano ${ }^{3}$, Esther M. Medrano-Sánchez ${ }^{3}$, \\ Alberto Armijo ${ }^{1}$, Ana Fernández-Palacín ${ }^{4}$, José Antonio García-Mejido ${ }^{1,2}$ ^ \\ ${ }^{1}$ Department of Obstetrics and Gynecology, Valme University Hospital, Seville, Spain; ${ }^{2}$ Department of Obstetrics and Gynecology, University of \\ Seville, Seville, Spain; ${ }^{3}$ Department of Physiotherapy. University of Seville, Seville, Spain; ${ }^{4}$ Biostatistics Unit, Department of Preventive Medicine \\ and Public Health, University of Seville, Seville, Spain
}

Contributions: (I) Conception and design: JA García-Mejido; (II) Administrative support: JA García-Mejido, JA Sainz-Bueno; (III) Provision of study materials or patients: JA García-Mejido, MJ Bonomi, C Suárez-Serrano, EM Medrano-Sánchez, A Armijo; (IV) Collection and assembly of data: JA García-Mejido, MJ Bonomi, C Suárez-Serrano, EM Medrano-Sánchez, A Armijo; (V) Data analysis and interpretation: JA García-Mejido, A Fernández-Palacín, JA Sainz-Bueno; (VI) Manuscript writing: All authors; (VII) Final approval of manuscript: All authors.

Correspondence to: José Antonio García Mejido. Department of Obstetrics and Gynecology, Valme University Hospital, Seville, Spain. Email: jgmejido@us.es; Ana Fernández-Palacín. Biostatistics Unit, Department of Preventive Medicine and Public Health, University of Seville, Seville, Spain. Email: afp@us.es.

Background: We believe that physiotherapy with muscle training (MT) of the postpartum pelvic floor may lead to a change in the clinical management of patients with avulsion of the puborectal portion of the levator ani muscle (LAM). Our objective is to assess whether physiotherapy with MT of the postpartum pelvic floor in patients with LAM avulsion produces changes in pelvic floor morphology evaluated by 3/4D transperineal ultrasound.

Methods: This parallel randomized controlled trial (RCT) included 97 primiparous patients. A study was conducted in three parts. In the first part ( 3 months postpartum), primiparous patients with LAM avulsion were recruited, and the levator hiatus and the LAM areas were measured using 3/4D transperineal ultrasound. In the second part ( 3 to 6 months postpartum), patients were randomized into two groups, with one undergoing rehabilitation (experimental group) and another without rehabilitation (control group). At the end of 6 months, a new transperineal ultrasound was performed. In the third part (9 months postpartum), the levator hiatus and LAM dimensions were analyzed again. The RCT was registered at ClinicalTrials. gov (NCT03686956). Project PI16/01387 funded by Instituto de Salud Carlos III (Spain) integrated in the national I+D+i 2013-2016 and cofounded by the European Union (ERDF/ESF, "Investing in your future").

Results: A total of 92 completed the study, including 46 patients in the experimental group and 46 in the control group. The experimental group had a greater LAM area at 6 months $\left(9.2 \pm 1.9 v s .7 .6 \pm 2.1 \mathrm{~cm}^{2}\right.$, $\mathrm{P}=0.008$; 95\% CI: 0.6-3.0) and 9 months after labor (9.4 \pm 2.7 vs. $7.6 \pm 2.0 \mathrm{~cm}^{2}, \mathrm{P}=0.012 ; 95 \%$ CI: 0.4-3.2), which was not observed at 3 months postpartum ( $8.3 \pm 1.6$ vs. $\left.7.5 \pm 2.3 \mathrm{~cm}^{2} ; \mathrm{P}=0.183 ; 95 \% \mathrm{CI}: 0.39-1.99\right)$. The levator hiatus area decreased more in the experimental group in almost all comparisons. The most significant change occurred from 3 to 6 months during the Valsalva maneuver $\left(-3.92 \pm 5.12\right.$ vs. $0.45 \pm 3.06 \mathrm{~cm}^{2} ; \mathrm{P}<0.005$; 95\% CI: 2.64-5.00).

Conclusions: Women with a rehabilitated LAM through physiotherapy showed a significant reduction in the levator hiatus area during Valsalva while receiving in-person physical therapy (3 to 6 months after

\footnotetext{
$\wedge$ ORCID: 0000-0002-3079-5583.
} 
delivery). These differences did not persist once physical therapy was completed (6 to 9 months after delivery).

Trial Registration: ClinicalTrials.gov identifier NCT03686956.

Keywords: Rehabilitation; pelvic floor; ultrasonography; birth injuries

Submitted Sep 01, 2021. Accepted for publication Dec 20, 2021; Published online: 24 Jan 2022.

doi: 10.21037/qims-21-877

View this article at: https://dx.doi.org/10.21037/qims-21-877

\section{Introduction}

Pregnancy induces changes in the pelvic floor. There is remodeling of the connective and muscular structures during pregnancy (1). Furthermore, additional injuries to the puborectal portion of the levator ani muscle (LAM) occur during childbirth. These injuries are caused by the changes that occur in the hiatus of the levator muscle to allow the passage of the fetal head during childbirth $(2,3)$, and they are present in 10-36\% of vaginal deliveries (4).

LAM avulsion defined, as an abnormal insertion of the puborectalis muscle at the level of the pubis (4), produces a larger levator hiatus area (5) and reduces the LAM area (6-8). The diagnosis of avulsion LAM by transperineal ultrasound is the most widely used technique, defining it as abnormal insertion of the muscle in the all three central slices (4) with levator-urethra gap $\geq 2.5 \mathrm{~cm}$ (9). In turn, LAM avulsion $(10,11)$ and ballooning (12) can lead to pelvic organ prolapse, especially of the anterior and central compartments, which are unrelated to stress urinary incontinence (13). For women with avulsion, the average latency between the first birth and the need for prolapse surgery has been observed to be 33.5 years (3-66 years) (14).

Knowing the consequences of LAM avulsion, it is logical to think that the prevention of muscle injury could be an important factor in reducing the incidence of pelvic floor dysfunction. Multiple factors that may influence the onset of LAM avulsion have been studied, such as a longer second stage of labor, greater fetal head circumference, higher fetal weight, Kristeller maneuver or an instrumented birth $(1,4,15-21)$. Despite known risk factors for avulsion, there are currently no preventive measures to decrease the incidence of avulsion during childbirth; for instance, no evidence of a protective effect of the Epi-No ${ }^{\circledR}$ device on intrapartum pelvic floor trauma. (22). It has also not been possible to predict the injury by intrapartum ultrasound (23); in fact, the prediction of LAM trauma before delivery can be difficult or even impossible (24). To all this it must be added that postnatal surgical repair of the levator injury has not been shown to be effective either (25).

Both the clinical management of LAM avulsion and avoidance of its long-term consequences are major challenges since it is an unpreventable (24) and irreparable injury (25). During the postpartum period, LAM avulsion has been shown to alter the strength, the contraction, and the resistance (26) of the pelvic floor. Hoff Brækken et al. described that the changes to the pelvic floor induced by muscle training (MT) (elevation of the bladder and rectum at rest, and the shrinking of the hiatus during maximum Valsalva) can be attributed to the hypertrophy of the LAM (thickness of the pubovisceral muscle) (27). However, the knowledge on the effect of MT in postpartum patients with avulsion LAM is limited. Therefore, strengthening the LAM in patients with avulsion is important during this period. Therefore, we believe that physiotherapy with MT of the postpartum pelvic floor may lead to a change in the clinical management of patients with LAM injuries, since it could facilitate LAM hypertrophy that counteracts the negative effects of avulsion LAM during the postpartum. We define physiotherapy with MT as rehabilitation program based on the hypopressive technique (three months in face-to-face sessions and individually at a rate of two 30-minute sessions per week), of active lumbopelvic stabilization exercises, including contraction of the pelvic floor muscles in the supine plank and quadruped positions, guided by the physiotherapists to guarantee correct performance. If we associate these aspects with the fact that there are no relevant studies on physiotherapy and changes in the ultrasound image of LAM, we propose our objective to evaluate whether MT, through physiotherapy, of the postpartum pelvic floor in patients with LAM avulsion produces changes in pelvic floor morphology evaluated by 3/4D transperineal ultrasound.

We present the following article in accordance with the CONSORT reporting checklist (available at https://qims. 
amegroups.com/article/view/10.21037/qims-21-877/rc).

\section{Methods}

\section{Study population}

This parallel randomized controlled trial (RCT) included a total of 97 primiparous women were recruited at the University Hospital of Valme (Hospital complex serving a population of 400,000 people) (Sevilla, Spain) between October 1, 2018 and September 1, 2019 (The period of time required was calculated based on the number of deliveries in our hospital). Patients were assigned by block randomization to one of the two study groups (doubleblinded): the experimental group and the control group.

Deliveries were assisted by professionals belonging to our maternity unit who had extensive experience. All deliveries were performed without the Kristeller maneuver and with protection of the maternal perineum at the moment of exit of the fetal head. Selective episiotomy (mediolateral) was carried out following our hospital's clinical practice guidelines.

The following obstetric parameters were evaluated: maternal age, gestational age, induction of labor, epidural status, duration of the second stage of labor, fetal head position, type of delivery, episiotomy, perineal tears $\left(1^{\text {st }}\right.$ degree: laceration of vaginal epithelium or perineal skin only; $2^{\text {nd }}$ degree: involvement of the perineal muscle but not the anal sphincter; $3^{\text {rd }}$ degree: disruption of the anal sphincter muscles; $4^{\text {th }}$ degree: third degree tear with disruption of the anal epithelium as well), and fetal head circumference.

Patients were recruited three months after delivery, including primiparous women who accepted and signed an informed consent form for participation in the study with a single term pregnancy (37-42 weeks of gestation), an eutocic vaginal delivery with a cephalic presentation and a fetal weight greater than 3,500 grams or vacuum-assisted or forceps delivery, no history of previous pregnancies, and no previous surgical interventions for pelvic floor repair. Patients without LAM avulsion or who presented some type of postpartum pelvic floor dysfunction (pelvic organ prolapse, urinary or fecal incontinence, sexual dysfunction or pelvic pain) were excluded.

\section{Examination method}

An ultrasound evaluation was performed with a Toshiba Aplio
$500^{\circledR}$ ultrasound system (Toshiba Medical Systems Corp., Tokyo, Japan) with 3D abdominal probe PVT-675 MV. Images were acquired with patients in dorsal lithotomy on a gynecological examination table, with an empty bladder placing the transducer on the perineum carefully, exerting the minimum possible pressure. Three volumes were captured for each patient: at rest, during Valsalva, and at maximum contraction (an objective and reliable method) $(28,29)$. Before the ultrasound, the patients were instructed by the examiner to perform a correct Valsalva maneuver and maximum contraction.

The ultrasound evaluation was performed by one expert in pelvic floor ultrasound (JAGM) (more than 5 years of experience in this area) who was blinded to the obstetric data of each birth. Avulsion was defined in the multiscreen ultrasound as an abnormal insertion of the LAM in the inferior pubic ramus, identified in the plane of minimal dimensions (PMD) and the two cranial slices at $2.5 \mathrm{~mm}$ $(10,30)$. LAM insertion was observed in the three central sections. In unclear cases, a levator-urethra gap $\geq 2.5 \mathrm{~cm}$ was used to define an abnormal insertion. From the PMD, the anteroposterior, transverse, and levator hiatus diameters were also determined (31). Increases in these measurements in patients with LAM avulsion have been described previously (level of evidence II) (1). The LAM area (31) was studied at rest in the PMD (Figure 1).

Physiotherapists were responsible for physiotherapy, and the patients were unaware of the type of avulsion (unilateral or bilateral) and the ultrasound measurements. The second phase, or the MT phase, lasted from 3 months to 6 months after delivery. Physiotherapy was applied to the experimental group by two physiotherapists specializing in pelvic floor dysfunction with more than 15 years of experience in this field (CS, EM). The physiotherapist evaluated that the patients could perform the exercises correctly on their own.

Therapy targeting muscular hypertrophy lasted three months in face-to-face sessions and individually at a rate of two 30-minute per sessions (1 sessions per week). The program consisted of pelvic floor exercises assisted by manometric biofeedback, which were performed in the supine position (with flexed legs). The rehabilitation program based on the hypopressive technique was the same for all women, performed with the automatic urogynecolgy testing of the PHENIX digital manometer (ELECTRONIC CONCEPT LIGNON INNOVATION. VIVALTIS). In addition, active lumbopelvic stabilization exercises, including contraction of the pelvic floor muscles in the 

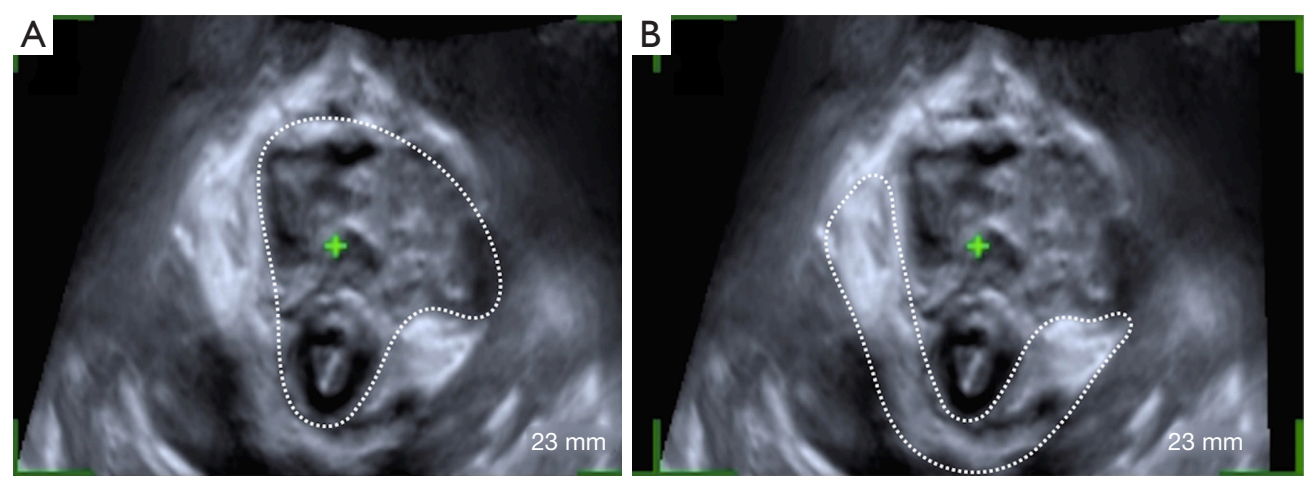

Figure 1 Measurement of the levator hiatus. (A) Levator hiatus area. (B) Levator ani muscle area.

supine plank and quadruped positions, were guided by the physiotherapists to guarantee correct performance.

Together with the treatment at the clinic, patients were asked to perform a series of exercises at home: 8-12 sustained contractions of $6 \mathrm{~s}$, with a rest period of double the exercise time, followed by $3-5$ fast contractions of $2 \mathrm{~s}$ at maximum intensity, again followed by resting double the exercise time (2 sessions per week). Domiciliary exercises were performed in supine, siting and standing position. Adherence to in-home treatment was assessed through weekly phone calls by the physiotherapists, and patients were considered completely adherent when they exceeded $90 \%$ of the indicated sessions. None of the participants suffered adverse effects from the intervention performed.

The control group received an information brochure with recommendations, including the same program of pelvic floor exercises taught to the patients in the experimental group, but without any kind of supervision by the physiotherapist.

At the end of this phase (6 months after delivery), the second postdelivery ultrasound was performed, where the measurements of the levator hiatus area and LAM area were reassessed. Between 6 and 9 months, all participants underwent a physiotherapy rest period.

The last part of the study consisted of $3 / 4 \mathrm{D}$ transperineal ultrasound at 9 months postpartum, where the measurements of the levator hiatus area and LAM area were analyzed again.

Participants, those administering the intervention (physiotherapist), and those assessing the outcome (the data collectors and analysts) were blinded to the group allocation.

\section{Sample size}

To detect a $15 \%$ difference in the reduction of the size of the levator hiatus area of the LAM between the study groups (control/experimental) at 6 months after the intervention, considering a common standard deviation of $10 \%$ (from a pilot study), an $\alpha$ of $5 \%$, and a power of $80 \%$ and assuming a loss rate of $10 \%$ in the follow-up, we needed 46 women in each group.

Currently, the trial is closed for recruitment and followup, since the sample size was sufficient based on the objectives set and the number of participants included in the analysis for each intervention group were analyzed according to the original group assignment. Start date of patient recruitment: October 1, 2018. End date of patient recruitment: December 1, 2018. End date of follow-up in the result: September 1, 2019.

The randomization procedure used for the assignment to one of the two groups: experimental group (A)/control group (B) has been a randomization by blocks. This procedure attempts to alleviate the problems that arise when performing a simple randomization (uneven number of patients per group, non-homogeneous distribution of prognostic factors between groups, etc.). To avoid the above problems, we have used the block-balanced randomization technique. In this case, the randomization has been carried out using the program nQuery Advisor Release 7.0, which automatically assigns the same number of patients in the experimental group (A) and in the control group (B) for blocks of 4 patients (the size of the block is always a multiple of the number of groups), with the same number of patients in each group and without the possibility that at the end of a block the researcher 
knows which treatment to assign. The method used by the software to do this for blocks of 4 patients is to generate all possible combinations ignoring those with uneven location. These combinations are: $\mathrm{AABB}, \mathrm{ABAB}$, ABBA, BABA, BAAB, and BBAA. These combinations are assigned numbers from 1 to 6 and use a random number generator for your choice. Suppose the sequence is 534, then the BAAB ABBA and BABA blocks would be generated for the first 12 patients. If the numbers 7 , 8,9 or 0 appear they are ignored. The mechanism used to implement the random allocation sequence was done by sequentially numbered opaque sealed envelope. The MJBB researcher, who generated the allocation sequence according to the randomization and who enrolled the participants, assigned the patients to the physiotherapists following the allocation by blocks.

\section{Statistical analysis}

The data analysis was carried out by protocol. Our primary results were changes in the measurements of the levator hiatus area (rest, contraction, and Valsalva) between the different phases of the study, and our secondary results were changes in the measurements of the LAM area (rest, contraction, and Valsalva) between the different phases of the study.

In the total sample and in the two study groups (control, experimental), the quantitative variables are described by means and standard deviations. Qualitative variables are written as percentages. For the comparison of the initial values of the numerical variables between the two groups, Student's $t$-test was performed if the data were normally distributed, and the Mann-Whitney U-test was performed for nonnormally distributed data. For the qualitative variables, contingency tables and the chi-squared or Fisher's exact test were used.

To analyze the change in levator hiatus dimensions at 3,6 , and 9 months in the two treatment groups (control, experimental), a general linear model of repeated measures (one-way repeated-measures MANOVA) was applied with two pathways or factors. The intrasubject factor was the measurement times: 3, 6, and 9 months; and the intersubject factor was the group: control or experimental.

The above tests were complemented with $95 \%$ CIs to quantify the effect size. The data analysis was performed with the statistical package IBM SPSS Statistics 26 for Windows.

\section{Ethical approval}

The study was approved by the local Ethics and Research Committee (No. 0545-N-18) on 29-05-2018. The RCT was registered at ClinicalTrials.gov (NCT03686956). All patients gave their written informed consent before starting the study. The study was conducted in accordance with the Declaration of Helsinki (as revised in 2013).

\section{Results}

Of the 209 initial patients who attended the first ultrasound examination 3 months after delivery, 97 (46.4\%) were included in the study, and 92 completed the study, including 46 patients in the experimental group and 46 in the control group. The recruitment of patients is shown in Figure 2. The general and obstetric characteristics of the general population, the excluded patients, those lost to follow-up, and those studied are listed in Table 1.

Comparisons of the levator hiatus dimensions and the LAM area are shown in Table 2. The experimental group had a larger LAM area at 6 months $\left(9.2 \pm 1.9 v s .7 .6 \pm 2.1 \mathrm{~cm}^{2}\right.$, $\mathrm{P}=0.008)$ and at 9 months postpartum $\left(9.4 \pm 2.7\right.$ vs. $7.6 \pm 2.0 \mathrm{~cm}^{2}$; $\mathrm{P}=0.012)$, which was not present at 3 months postpartum $\left(8.3 \pm 1.6\right.$ vs. $\left.7.5 \pm 2.3 \mathrm{~cm}^{2} ; \mathrm{P}=0.183\right)$. The graphical comparison of the changes in the hiatus area of the levator muscle at rest and at contraction is shown in Figure 3. Patients in the experimental group (blue line) showed a lower levator area at 6 and 9 months than patients in the control group (red line) both at rest and during contraction.

The difference in the areas of the LAM hiatus between the experimental group and the control group in all three phases of study are presented in Table 3. The levator hiatus area was smaller in the experimental group in almost all comparisons. The major change occurred between 3 and 6 months during the Valsalva maneuver $(-3.92 \pm 5.12$ vs. $\left.0.45 \pm 3.06 \mathrm{~cm}^{2} ; \mathrm{P}<0.005\right)$, that supposes a decrease of the change of the Levator hiatus area (Valsava) of $971 \%$.

\section{Discussion}

This is the first clinical trial that studied the behavior of muscle structures in patients with LAM avulsion after postpartum MT. We observed that women with avulsion rehabilitated through physiotherapy had a significant reduction in the levator hiatus area during the Valsalva maneuver while receiving physical therapy (3 to 6 months after delivery). These differences did not persist once in- 


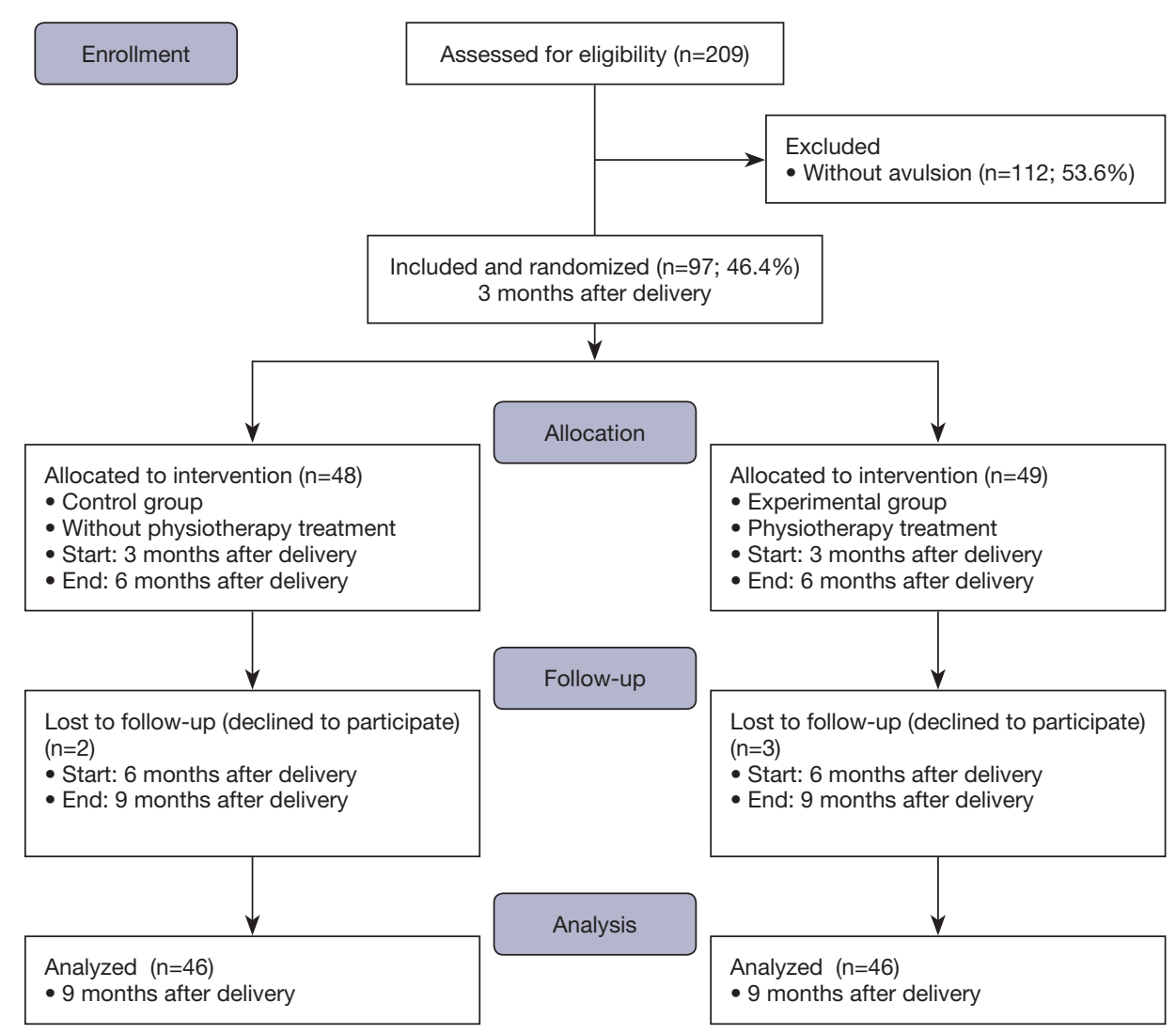

Figure 2 Patient recruitment.

person physiotherapy was completed (6 to 9 months after delivery).

In LAM avulsion patients, during the postpartum period, the passive properties of LAM are altered, such as strength, contraction rate, and resistance (26). Because of this, pelvic MT should be the first line of treatment in patients with LAM avulsion (26). These changes have also been described in patients with urinary incontinence and pelvic organ prolapse (32-34). Therefore, postpartum rehabilitation, by improving the function and muscle strength of the pelvic floor, increases overall quality of life and leads to a high rate of satisfaction among patients $(35,36)$. However, none of these aspects (strength, resistance, urinary incontinence, pelvic organ prolapse, quality of life, satisfaction) were evaluated in our clinical trial.

The changes to the pelvic floor induced by MT can be attributed to the hypertrophy of the LAM, the elevation of the bladder and rectum at rest, and the shrinking of the hiatus during maximum Valsalva (27). These modifications could be due to changes in collagen, muscle tissue, and other morphological adaptations achieved by MT (37). We believe that the effect of the muscular hypertrophy that we observed in our patients is due to the type of strength training protocol. However, we observe that the levator hiatus area during Valsalva increases again when we give up the MT. This suggests that to maintain a lower levator hiatus area during Valsalva, it is necessary to maintain a constant MT over time. Not all rehabilitation protocols for the pelvic floor have the same effect on the musculature (38). Therefore, some authors have suggested that MT is not effective in patients with pelvic organ prolapse with or without postpartum LAM injuries (39) in contrast to other authors (40-42). However, Hoff Brækken et al. (27) found that supervised MT of the pelvic floor can increase muscle volume and thus close the levator hiatus. The work of Hoff Brækken et al. (27) is consistent with the study by Juez et al. (43) and with our work in patients with LAM avulsion (Figure 3).

The main strength of our study is its design. The study was a RCT evaluating changes in pelvic floor morphology as evaluated postpartum by $3 / 4 \mathrm{D}$ transperineal ultrasound in patients with LAM avulsion. We followed up the 
Table 1 Obstetric and general characteristics

\begin{tabular}{|c|c|c|}
\hline & $\begin{array}{l}\text { Experimental } \\
\text { group }(n=46)\end{array}$ & $\begin{array}{c}\text { Control group } \\
\qquad(\mathrm{n}=46)\end{array}$ \\
\hline Maternal age & $30.4 \pm 5.3$ & $31.4 \pm 5.3$ \\
\hline Gestational age & $39.7 \pm 1.2$ & $39.4 \pm 1.3$ \\
\hline Induced labor & $8(17.4)$ & $6(13.0)$ \\
\hline Epidural anesthesia & $40(87.0)$ & $42(91.3)$ \\
\hline $\begin{array}{l}\text { Epidural anesthesia duration } \\
\text { (min) }\end{array}$ & $520.7 \pm 232.6$ & $529.8 \pm 282.5$ \\
\hline $\begin{array}{l}\text { Second stage of labor duration } \\
\text { (min) }\end{array}$ & $104.4 \pm 58.3$ & $85.9 \pm 56.1$ \\
\hline Vacuum delivery & $32(69.6)$ & $38(82.6)$ \\
\hline Forceps delivery & $12(26.1)$ & $8(17.3)$ \\
\hline \multicolumn{3}{|l|}{ Fetal head position } \\
\hline Anterior & $42(91.3)$ & $42(91.3)$ \\
\hline Posterior & $2(4.3)$ & $0(0)$ \\
\hline Right transverse & $0(0)$ & $4(8.7)$ \\
\hline Left transverse & $2(4.3)$ & $0(0)$ \\
\hline Episiotomy & $44(95.7)$ & $42(91.3)$ \\
\hline Perineal tears & $26(56.5)$ & $32(69.6)$ \\
\hline Grade I & $2(7.7)$ & $8(25.0)$ \\
\hline Grade II & $14(53.8)$ & $12(37.6)$ \\
\hline Grade III & $10(38.5)$ & $6(18.7)$ \\
\hline Grade IV & $0(0)$ & $6(18.7)$ \\
\hline Fetal head circumference (cm) & $35.5 \pm 1.4$ & $35.1 \pm 1.2$ \\
\hline
\end{tabular}

Data presented as mean \pm SD or $n(\%)$. SD, standard deviation.

patients after the MT period, which was longer than that performed in previous studies (43). In addition, we included asymptomatic patients, assuming that adherence to treatment was due to the motivation of the study subjects and not to a specific pathology, thus reducing possible confounding variables. In our study, the control group received an information brochure with recommendations since we considered offering any type of treatment to these patients to be unethical. Adherence to treatment in this group was evaluated by telephone as in the experimental group. One of the limitations of our study is that our results were not correlated with the possible pelvic floor dysfunctions existing in each group. Also more details about ultrasound measurement and analysis are needed, differentiating the type of avulsion (uni- or bilateral).

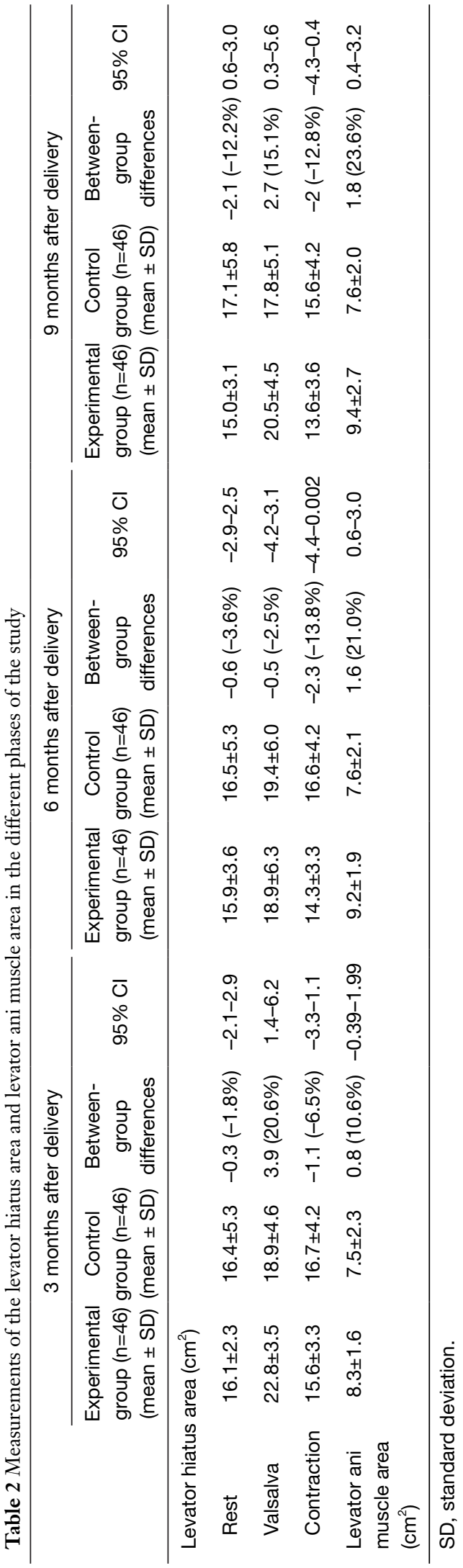



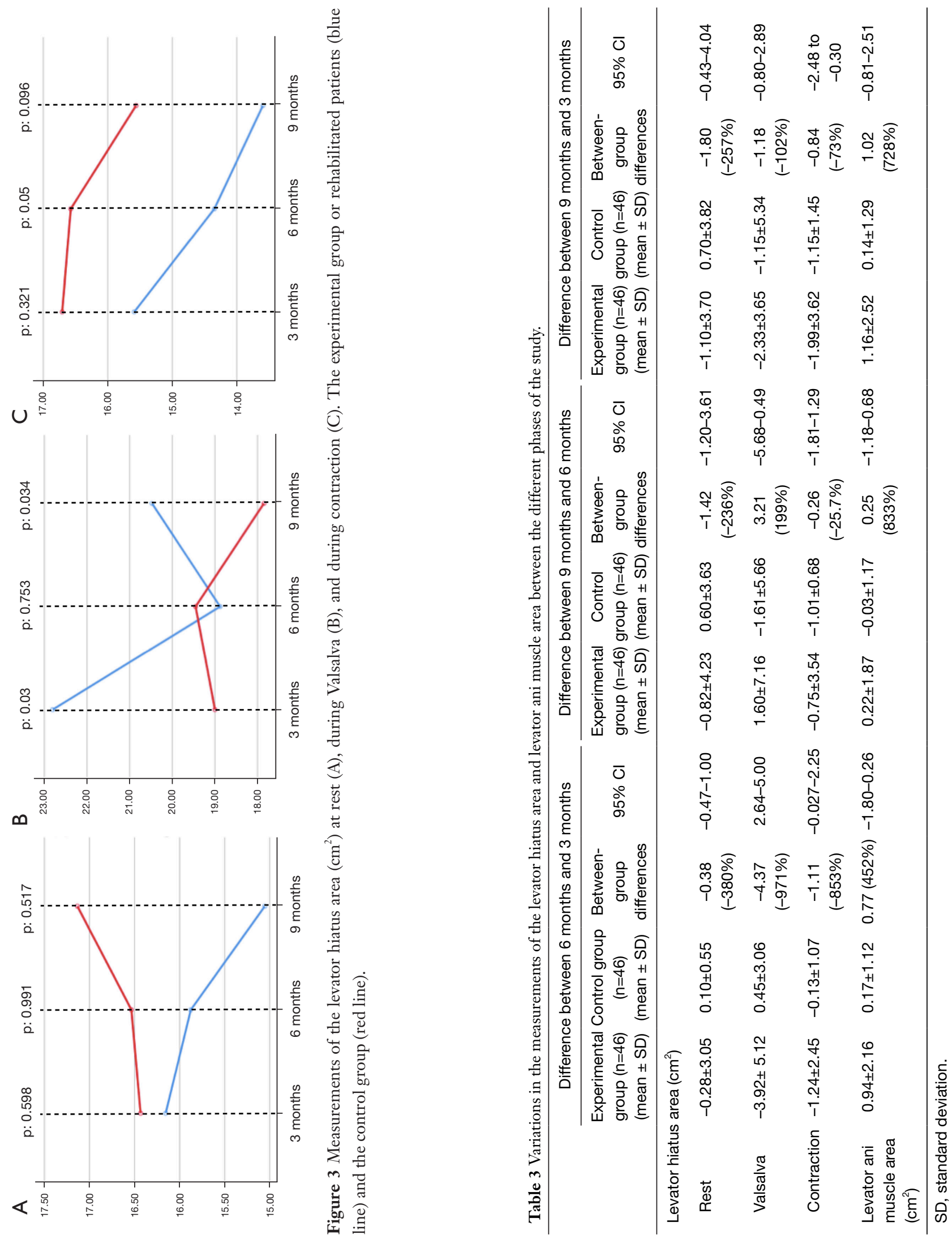
Although we found a reduction in the levator hiatus area and an increase in the LAM area in our study, these differences were somewhat smaller than those initially expected. Our data should be taken into consideration for future clinical trials.

\section{Conclusions}

This is the first clinical trial to study 3/4D ultrasound morphological changes in the pelvic floor induced by postpartum MT through physiotherapy in patients with LAM avulsion. We observed that women with avulsion rehabilitated by physiotherapy showed a significant reduction in the levator hiatus area during the Valsalva maneuver while receiving in-person physical therapy (3 to 6 months after delivery). These differences did not persist once physical therapy was completed (6 to 9 months after delivery).

\section{Acknowledgments}

Funding: We acknowledge the support of Project PI16/01387 funded by Instituto de Salud Carlos III integrated in the national I+D+i 2013-2016 and co-funded by the European Union (ERDF/ESF, "Investing in your future").

\section{Footnote}

Reporting Checklist: The authors have completed the CONSORT reporting checklist. Available at https://qims. amegroups.com/article/view/10.21037/qims-21-877/rc

Conflicts of Interest: All authors have completed the ICMJE uniform disclosure form (available at https://qims. amegroups.com/article/view/10.21037/qims-21-877/coif). The authors have no conflicts of interest to declare.

Ethical Statement: The authors are accountable for all aspects of the work in ensuring that questions related to the accuracy or integrity of any part of the work are appropriately investigated and resolved. The study was conducted in accordance with the Declaration of Helsinki (as revised in 2013). The study was approved by the local Ethics and Research Committee (No. 0545-N-18) on 2905-2018. The RCT was registered at ClinicalTrials.gov (NCT03686956). All patients gave their written informed consent before starting the study.

Open Access Statement: This is an Open Access article distributed in accordance with the Creative Commons Attribution-NonCommercial-NoDerivs 4.0 International License (CC BY-NC-ND 4.0), which permits the noncommercial replication and distribution of the article with the strict proviso that no changes or edits are made and the original work is properly cited (including links to both the formal publication through the relevant DOI and the license). See: https://creativecommons.org/licenses/by-nc-nd/4.0/.

\section{References}

1. Shek KL, Dietz HP. The effect of childbirth on hiatal dimensions. Obstet Gynecol 2009;113:1272-8.

2. García Mejido JA, Suárez Serrano CM, Fernéndez Palacín A, Aquise Pino A, Bonomi Barby MJ, Sainz Bueno JA. Evaluation of levator ani muscle throughout the different stages of labor by transperineal 3D ultrasound. Neurourol Urodyn 2017;36:1776-81.

3. García-Mejido JA, Fernández-Palacín A, Suarez-Serrano CM, Medrano-Sanchez E, Sainz JA. Successive intraand postpartum measurements of levator-urethra gap to establish timing of levator avulsion. Ultrasound Obstet Gynecol 2019;54:840-2.

4. Schwertner-Tiepelmann N, Thakar R, Sultan AH, Tunn R. Obstetric levator ani muscle injuries: current status. Ultrasound Obstet Gynecol 2012;39:372-83.

5. Dietz HP, Franco AV, Shek KL, Kirby A. Avulsion injury and levator hiatal ballooning: two independent risk factors for prolapse? An observational study. Acta Obstet Gynecol Scand 2012;91:211-4.

6. DeLancey JO, Morgan DM, Fenner DE, Kearney R, Guire K, Miller JM, Hussain H, Umek W, Hsu Y, AshtonMiller JA. Comparison of levator ani muscle defects and function in women with and without pelvic organ prolapse. Obstet Gynecol 2007;109:295-302.

7. Dietz HP, Shek C. Levator avulsion and grading of pelvic floor muscle strength. Int Urogynecol J Pelvic Floor Dysfunct 2008;19:633-6.

8. Nyhus MØ, Salvesen KA, Volløyhaug I. Association between pelvic floor muscle trauma and contraction in parous women from a general population. Ultrasound Obstet Gynecol 2019;53:262-8.

9. Dietz HP, Garnham AP, Rojas RG. Is the levator-urethra gap helpful for diagnosing avulsion? Int Urogynecol J 2016;27:909-13.

10. Dietz HP, Bernardo MJ, Kirby A, Shek KL. Minimal criteria for the diagnosis of avulsion of the puborectalis muscle by tomographic ultrasound. Int Urogynecol J 
2011;22:699-704.

11. Cheung RYK, Chan SSC, Shek KL, Chung TKH, Dietz HP. Pelvic organ prolapse in Caucasian and East Asian women: a comparative study. Ultrasound Obstet Gynecol 2019;53:541-5.

12. Xuan Y, Friedman T, Dietz HP. Does levator ani hiatal area configuration affect pelvic organ prolapse? Ultrasound Obstet Gynecol 2019;54:124-7.

13. García Mejido JA, Valdivieso Mejias P, Fernández Palacín A, Bonomi Barby MJ, De la Fuente Vaquero P, Sainz Bueno JA. Evaluation of isolated urinary stress incontinence according to the type of levator ani muscle lesion using 3/4D transperineal ultrasound 36 months post-partum. Int Urogynecol J 2017;28:1019-26.

14. Thomas V, Shek KL, Guzmán Rojas R, Dietz HP. Temporal latency between pelvic floor trauma and presentation for prolapse surgery: a retrospective observational study. Int Urogynecol J 2015;26:1185-9.

15. Garcia-Mejido JA, Gutierrez-Palomino L, Borrero C, Valdivieso P, Fernandez-Palacin A, Sainz-Bueno JA. Factors that influence the development of avulsion of the levator ani muscle in eutocic deliveries: 3-4D transperineal ultrasound study. J Matern Fetal Neonatal Med 2016;29:3183-6.

16. Shek KL, Dietz HP. Intrapartum risk factors for levator trauma. BJOG 2010;117:1485-92.

17. Dietz HP. Forceps: towards obsolescence or revival? Acta Obstet Gynecol Scand 2015;94:347-51.

18. Garcia-Mejido JA, Gutierrez L, Fernandez-Palacín A, Aquise A, Sainz JA. Levator ani muscle injuries associated with vaginal vacuum assisted delivery determined by $3 / 4 \mathrm{D}$ transperineal ultrasound. J Matern Fetal Neonatal Med 2017;30:1891-6.

19. García-Mejido JA, Martín-Martínez A, González-Diaz E, Fernández-Fernández C, Ortega I, Medina M, FernándezCorona A, Fernández-Palacín A, Sainz JA. Malmström vacuum or Kielland forceps: which causes more damage to pelvic floor? Ultrasound Obstet Gynecol 2020;55:257-63.

20. Volløyhaug I, Taithongchai A, Van Gruting I, Sultan A, Thakar R. Levator ani muscle morphology and function in women with obstetric anal sphincter injury. Ultrasound Obstet Gynecol 2019;53:410-6.

21. Youssef A, Salsi G, Cataneo I, Pacella G, Azzarone C, Paganotto MC, Krsmanovic J, Montaguti E, Cariello L, Bellussi F, Rizzo N, Pilu G. Fundal pressure in second stage of labor (Kristeller maneuver) is associated with increased risk of levator ani muscle avulsion. Ultrasound Obstet Gynecol 2019;53:95-100.
22. Kamisan Atan I, Shek KL, Langer S, Guzman Rojas R, Caudwell-Hall J, Daly JO, Dietz HP. Does the Epi-No(®) birth trainer prevent vaginal birth-related pelvic floor trauma? A multicentre prospective randomised controlled trial. BJOG 2016;123:995-1003.

23. García-Mejido JA, de la Fuente-Vaquero P, Aquise-Pino A, Castro-Portillo L, Fernández-Palacín A, Sainz-Bueno JA. Can we predict levator ani muscle avulsion in instrumental deliveries through intrapartum transperineal ultrasound? J Matern Fetal Neonatal Med 2019;32:3137-44.

24. Shek KL, Dietz HP. Can levator avulsion be predicted antenatally? Am J Obstet Gynecol 2010;202:586.e1-6.

25. Dietz HP, Gillespie AV, Phadke P. Avulsion of the pubovisceral muscle associated with large vaginal tear after normal vaginal delivery at term. Aust N Z J Obstet Gynaecol 2007;47:341-4.

26. Cyr MP, Kruger J, Wong V, Dumoulin C, Girard I, Morin M. Pelvic floor morphometry and function in women with and without puborectalis avulsion in the early postpartum period. Am J Obstet Gynecol 2017;216:274.e1-8.

27. Hoff Brækken I, Majida M, Engh ME, Bø K. Morphological changes after pelvic floor muscle training measured by 3-dimensional ultrasonography: a randomized controlled trial. Obstet Gynecol 2010;115:317-24.

28. Nyhus MØ, Oversand SH, Salvesen $\varnothing$, Salvesen KA, Mathew S, Volløyhaug I. Ultrasound assessment of pelvic floor muscle contraction: reliability and development of an ultrasound-based contraction scale. Ultrasound Obstet Gynecol 2020;55:125-31.

29. Nyhus MØ, Oversand SH, Mathew S, Salvesen KA, Volløyhaug I. OC27.05: Reliability study of transperineal ultrasound for assessment of pelvic floor contraction. Ultrasound Obstet Gynecol 2019;54:71.

30. Dietz HP, Pattillo Garnham A, Guzmán Rojas R. Is it necessary to diagnose levator avulsion on pelvic floor muscle contraction? Ultrasound Obstet Gynecol 2017;49:252-6.

31. van den Noort F, van der Vaart CH, Grob ATM, van de Waarsenburg MK, Slump CH, van Stralen M. Deep learning enables automatic quantitative assessment of puborectalis muscle and urogenital hiatus in plane of minimal hiatal dimensions. Ultrasound Obstet Gynecol 2019;54:270-5.

32. Braekken IH, Majida M, Ellström Engh M, Holme IM, Вø K. Pelvic floor function is independently associated with pelvic organ prolapse. BJOG 2009;116:1706-14.

33. Diez-Itza I, Arrue M, Ibañez L, Paredes J, Murgiondo A, Sarasqueta C. Postpartum impairment of pelvic floor 
muscle function: factors involved and association with prolapse. Int Urogynecol J 2011;22:1505-11.

34. Morin M, Bourbonnais D, Gravel D, Dumoulin C, Lemieux MC. Pelvic floor muscle function in continent and stress urinary incontinent women using dynamometric measurements. Neurourol Urodyn 2004;23:668-74.

35. Gagnon LH, Boucher J, Robert M. Impact of pelvic floor muscle training in the postpartum period. Int Urogynecol J 2016;27:255-60.

36. Mosalanejad F, Afrasiabifar A, Zoladl M. Investigating the combined effect of pelvic floor muscle exercise and mindfulness on sexual function in women with multiple sclerosis: a randomized controlled trial. Clin Rehabil 2018;32:1340-7.

37. Folland JP, Williams AG. The adaptations to strength training : morphological and neurological contributions to increased strength. Sports Med 2007;37:145-68.

38. Bø K, Hilde G, Stær-Jensen J, Brækken IH. Can the Paula method facilitate co-contraction of the pelvic floor muscles? A 4D ultrasound study. Int Urogynecol J 2011;22:671-6.

39. Bø K, Hilde G, Stær-Jensen J, Siafarikas F, Tennfjord MK, Engh ME. Postpartum pelvic floor muscle training and

Cite this article as: Sainz-Bueno JA, Bonomi MJ, Suárez-Serrano C, Medrano-Sánchez EM, Armijo A, Fernández-Palacín A, García-Mejido JA. Quantification of 3/4D ultrasound pelvic floor changes induced by postpartum muscle training in patients with levator ani muscle avulsion: a parallel randomized controlled trial. Quant Imaging Med Surg 2022;12(4):2213-2223. doi: 10.21037/qims-21-877 pelvic organ prolapse--a randomized trial of primiparous women. Am J Obstet Gynecol 2015;212:38.e1-7.

40. Hagen S, Stark D, Glazener C, Dickson S, Barry S, Elders A, Frawley H, Galea MP, Logan J, McDonald A, McPherson G, Moore KH, Norrie J, Walker A, Wilson D; POPPY Trial Collaborators. Individualised pelvic floor muscle training in women with pelvic organ prolapse (POPPY): a multicentre randomised controlled trial. Lancet 2014;383:796-806.

41. Nyhus MØ, Mathew S, Salvesen KA, Volløyhaug I. OC27.01: A randomised controlled trial of the effect of pelvic floor exercise on contraction, anatomy and symptoms in women scheduled for prolapse surgery. Ultrasound Obstet Gynecol 2019;54:70.

42. Gu X, Yang M. OC27.02: Effect on bladder prolapse of individualised Kegel exercise supervised by ultrasound. Ultrasound Obstet Gynecol 2019;54:70.

43. Juez L, Núñez-Córdoba JM, Couso N, Aubá M, Alcázar JL, Mínguez JÁ. Hypopressive technique versus pelvic floor muscle training for postpartum pelvic floor rehabilitation: A prospective cohort study. Neurourol Urodyn 2019;38:1924-31. 